\title{
The effect of instructions upon Necker Cube reversal '
}

LAURA WOLF, GLENNA FORD, ROSEMARY COGAN AND DENNIS COGAN

TEXAS TECHNOLOGICAL COLLEGE

The effect of ego-involving suggestion on perception of Necker Cube reversals was examined. It was hypothesized that Ss told that "intelligent people see more reversals," would report more reversals (Group $\mathrm{H}-\mathrm{H}$ ), and Ss told that "intelligent people see less reversals," would report less reversals (Group H-L). Both groups were expected to differ from a non-suggestion group (Group C). The difference between groups was reliable. Multiple comparisons indicated that Group H-L had reliably fewer reversals that either Group C or Group $\mathrm{H}-\mathrm{H}$, which did not differ from each other. The lack of difference between Groups $\mathrm{H}-\mathrm{H}$ and $\mathrm{C}$ may have been due to an elevation of reversal rate in Group $\mathrm{C}$ because of the achievement motivation characteristic of the college student.

Much research on Necker Cubes has been concerned with the stimulus factors influencing the perception of this figure, but relatively few experiments have been concerned with the effects of suggestion or instructions on reversal rate. Meredith \& Meredith (1962) demonstrated that instructions have a significant effect on the rate of binocular rivalry, an alternation phenomenon thought by many to be related to Necker Cube and other alternation phenomena. They used three different instructional conditions: Group 1 was instructed not to try to control the rate of alternation; Group 2 was instructed to make alternations occur as rapidly as possible; and Group 3 was instructed to make alternations occur as slowly as possible. The differences between the three groups were reliable. Cappone (1963) showed that Ss perceived the Ames trapezoidal illusion at a significantly greater rate after the administration of positive verbal suggestion. McGee (1963), using instructions that correlated high alternation rate with success, found that this type of positive verbal suggestion increased the perceptual frequency rate of the Ames trapezoidal illusion. Groups told how they were doing improved, while a noninformed group continued to see the same number of reversals throughout the experiment. McGee's results indicated that suggestion seems to operate as a modifying power in an ambiguous stimulus situation by creating an external frame of reference on which the $S$ can base his judgments. In an experiment by Franks \& Lindahl (1963) there were two conditions. In the Hold condition the Ss were instructed to try and hold any one percept as long as possible; in the Natural condition Ss were instructed to relax and let changes occur naturally. Their results indicated that instructions were effective in reducing the rate of reversal of the Necker Cube.
In order to clarify the influence of suggestion, the present experiment was designed to test the effect of ego-involving suggestion on the rate of reported reversal of a Necker Cube.

Subjects

Ss were 30 college students, volunteers from a second semester introductory psychology course, chosen randomly without regard to sex. Ss were not screened for visual defects.

\section{Apparafus}

The perception figure was a 1 in. sq. Necker Cube, a black outline on a white, $8 \times 11$ in. sheet of typing paper.

\section{Experimental Design}

Thirty Ss were divided into three groups of $10 \mathrm{Ss}$ each. Group $\mathrm{H}-\mathrm{H}$ was told that people of higher intelligence tend to see a higher reversal rate than do people of lower intelligence. Group $\mathrm{H}-\mathrm{L}$ was told that people of higher intelligence tend to see a lower reversal rate than do people of lower intelligence. Group $\mathrm{C}$ served as a non-suggestion control.

A completely randomized analysis of variance was run to test the difference between groups. The Duncan's new multiple range test was run to test where the differences between the means were reliable.

Procedure

Ss for each condition were assembled together in one room with the three Es (Es 1 and 2 were female, E 3 was male) who conducted the experiment. Instructions read to Group $\mathrm{H}-\mathrm{H}$ by $\mathrm{E} 3$ were as follows: "The results of recent experiments give us reason to expect that more intelligent people see more reversals in the Necker Cube." The instructions read to Group H-L by E 1 were as follows: "The results of recent experiments give us reason to expect that more intelligent people see less reversals in the Necker Cube." Group C was read a set of neutral instructions. Then Ss were allowed to view the figure until they saw it reverse once.

The Ss were then taken individually to another room where they were seated at a desk on which the test figure lay. E 1 read the instructions to $S, E 2$ tallied the number of responses, and $E 3$ recorded the time. Instructions to the $\mathrm{S}$ were, "Look at this figure and report to me each time your perception of it reverses, by raising your finger. The observation period will be $1 \mathrm{~min}$. Are you ready? Go." The method of reporting was used for the purpose of allowing the $S$ to keep his eyes on the figure with no verbal interruptions for the full $1 \mathrm{~min}$ viewing period. 


\section{Results and Discussion}

A completely randomized analysis of variance was run on the data. The difference between groups $\left(\overline{\mathrm{X}}_{\mathrm{H}-\mathrm{H}}=19.8, \overline{\mathrm{X}}_{\mathrm{H}-\mathrm{L}}=9.3, \overline{\mathrm{X}}_{\mathrm{C}}=20.4\right)$ was found to be reliable $(F=115.57, d f=2 / 27, p<.01)$. In order to make all possible comparisons, the Duncan's New Multiple Range Test was run. The difference between $H-L$ and $C$ was reliable $(p<.001)$; the difference between $\mathrm{H}-\mathrm{L}$ and $\mathrm{H}-\mathrm{H}$ was reliable $(p<.001)$; there was no reliable difference between Groups $\mathrm{H}-\mathrm{H}$ and $\mathrm{C}$.

These results indicate that suggestion to decrease the rate of reversal significantly affected rate of reversal, but that suggestion to increase reversal rate was not effective. The difference between Group $\mathrm{H}-\mathrm{L}$ and Group $C$ seems to substantiate the view taken by McGee that suggestion operates as a modifying power in an ambiguous stimulus situation by creating an external frame of reference on which the $\mathrm{S}$ can base his judgments. That is, the suggestion given to Group H-L would appear to have been substantial enough to motivate the Ss to try and decrease the number of reversals.

The failure of the $\mathrm{H}-\mathrm{H}$ group to increase the rate of reversal over that of Group $C$ may have been due to the fact that the positive suggestion did not provide a substantial frame of reference. The naive $\mathrm{Ss}$ in Group $\mathrm{H}-\mathrm{H}$ may have had no method of increasing the rate of reversal. It was informally noted by $\mathrm{E} 2$ that some of the $\mathrm{Ss}$ in $\mathrm{H}-\mathrm{H}$ seemed to increase their reversal rate in the latter part of the test period. This increase in rate of change during the viewing period is in accordance with the findings of Spitz \& Lipman (1962) and might indicate that Ss had developed methods of increasing reversal rate.

If it can be assumed that the suggestions used in the present investigation were ego-involving, these effects are compatible with data in the area of need achievement. Lowell (1952) found that persons having a high need achievement showed a high level of performance. As a result of the obvious achievement motivation in the college setting it may be that the rate of Group $\mathrm{C}$ was elevated even without the positive suggestion, which might account for the lack of difference between Groups $\mathrm{C}$ and $\mathrm{H}-\mathrm{H}$.

It would seem fruitful to replicate the present experiment using both high and low need for achievement Ss under the three instruction conditions.

Since the possibility always remains that verbal reports rather than perceptions per se were modified by the instructions, it would seem useful to devise some method of determining the accuracy of the S's verbal report.

\section{References}

Cappone, M. к. The effect of verbal suggestion on the reversal rate of the Ames trapezoidal illusion. Unpublished Master's Thesis, Fordham University, New York: 1963.

Franks, C. M., \& Lindahl, L. E. Extraversion and rate of fluctuation of the Necker Cube. Percept. mot. Skills, 1963, 16, 131-137.

Lowell, E. L The effect of need for achievement on learning of speed of performance. J. Psychol., 1952, 33, 31-40.

McGee, Mother Jane M. The effect of group verbal suggestion and age on the perception of the Ames trapezoidal illusion. J. Psychol., 1963, 56, 447-453.

Meredith, G. M., \& Meredith, C. G. W. Effect of instructional conditions on rate of binocular rivalry. Percept. mot. Skills, 1962, 15, 655-664.

Spitz, H. H., \& Lipman, R. S. Some factors affecting Necker Cube reversal rate. Percept. mot. Skills, 1962, 15, 611-625.

\section{Note}

1. The authors gratefully acknowledge the assistance of Ronald Horn in the initial stages of the project. 